\title{
Robotic versus laparoscopic low anterior resection for rectal cancer: a meta-analysis
}

\author{
Yanlai Sun ${ }^{\dagger}$, Huirong $\mathrm{Xu}^{\dagger}$, Zengjun $\mathrm{Li}^{*}$, Jianjun Han, Wentao Song, Junwei Wang and Zhongfa Xu*
}

\begin{abstract}
Background: The objective of this meta-analysis was to compare the clinical and oncologic outcomes of robotic low anterior resection (R-LAR) with conventional laparoscopic low anterior resection (L-LAR).

Methods: A search in the MEDLINE, Embase, and Ovid databases was performed for studies published before July 2014 that compared the clinical and oncologic outcomes of R-LAR and L-LAR. The methodological quality of the selected studies was assessed. Depending on statistical heterogeneity, a fixed or random effects model was used for the meta-analysis. The clinical and oncologic outcomes evaluated included operative time, estimated blood loss, length of hospital stay, rate of conversion to open surgery, post-operative complications, circumferential margin status, and number of lymph nodes collected.

Results: Eight studies, including 324 R-LAR cases and 268 conventional L-LAR cases, were analyzed. The metaanalysis showed that R-LAR was associated with a shorter hospital stay (mean difference $(M D)=-1.03 ; 95 \%$ confidence interval $(C \mathrm{Cl}=-1.78,-0.28 ; P=0.007$ ), lower conversion rate (odds ratio $(\mathrm{OR})=0.08 ; 95 \% \mathrm{Cl}=0.02,0.31$; $P=0.0002)$, lower rate of circumferential margin involvement $(\mathrm{OR}=0.5 ; 95 \% \mathrm{Cl}=0.25,1.01 ; P=0.05)$, and lower overall complication rate $(\mathrm{MD}=0.65 ; 95 \% \mathrm{Cl}=0.43,0.99 ; P=0.04)$ compared with L-LAR. There was no difference in operative time ( $M D=28.4 ; 95 \% \mathrm{Cl}=-3.48,60.27 ; P=0.08)$, the number of lymph nodes removed $(\mathrm{MD}=-0.63$; $95 \% \mathrm{Cl}=-0.78,2.05 ; P=0.38)$, and days to return of bowel function ( $\mathrm{MD}=-0.15 ; 95 \% \mathrm{Cl}=-0.37,0.06 ; P=0.17)$.
\end{abstract}

Conclusions: R-LAR was shown to be associated with a shorter hospital stay, lower conversion rate, lower rate of circumferential margin involvement, and lower overall complication rate compared with L-LAR. There were no differences in operative time, the number of lymph nodes removed, and days to return of bowel function.

Keywords: Rectal cancer, da Vinci Surgical System, Laparoscopic surgery, Low anterior resection, Meta-analysis

\section{Background}

Laparoscopic colorectal resection has been popularized due to its associated short length of hospital stay, reduced post-operative pain, and early return to normal bowel function [1, 2]; however, the laparoscopic colorectal technique has several drawbacks, such as a two-dimensional view and the limited dexterity of instruments due to the fixed instrument tips [3]. The da Vinci Surgical System was first used by colorectal surgeons in 2002 and was shown to overcome the drawbacks of conventional laparoscopic surgery. The da Vinci Surgical System allows for improved dexterity of movement, 3D and magnified vision, and tremor filtering [4]. Both laparoscopic and

\footnotetext{
* Correspondence: lizengjun676@163.com; xzfa2216@163.com

${ }^{\dagger}$ Equal contributors

Department of Colorectal Cancer Surgery, Shandong Cancer Hospital and Institute, 440 Jiyan Road, Jinan 250117, China
}

robotic surgeries for rectal cancer have been proven to be safe and effective. Thus far, there have been several studies comparing the clinical and oncologic outcomes of robotic versus laparoscopic surgery for rectal cancer [5-7], but few studies and no meta-analyses have been conducted comparing the outcomes of robotic (R-LAR) versus laparoscopic low anterior resection (L-LAR).

\section{Methods \\ Information sources and search}

A search in the MEDLINE, Embase, and Ovid databases was performed for studies published before July 2014 comparing clinical or oncologic outcomes of R-LAR and L-LAR. In addition, the abstracts published at major international conferences were manually searched. The following search terms were used: "robotic/robotic-assisted," 
"low anterior resection," "robotićrobotic-assisted versus laparoscopic rectal resection," and "robotic/roboticassisted versus laparoscopic low anterior resection."

\section{Study selection and quality assessment}

Two authors (SYL and XHR) obtained full-text articles of relevant studies and independently determined the criteria for inclusion. Disagreements between the two authors were resolved by discussion and consensus. If the negotiation failed, a third independent author (XZF) provided an opinion. The quality of RCTs was evaluated using the Cochrane Reviewer's Handbook Jadad scale [8], and the quality of the NRCTs was evaluated by the "Methodological Items for Non-randomized Studies" [9].

\section{Criteria for inclusion and exclusion}

The following inclusive criteria were required: (1) randomized or non-randomized studies comparing the clinical and oncologic outcomes of R-LAR and L-LAR; (2) if the same institution and/or authors reported more than one study, the higher quality study was included; (3) studies reported at least one of seven outcomes (operative time, estimated blood loss, length of hospital stay, conversion rate to open surgery, post-operative complications, circumferential margin status, and number of lymph nodes collected); and (4) the definition of the rectal cancer level should be below the peritoneal reflection.

The exclusion criteria were as follows: (1) the clinical and oncologic outcomes were not reported clearly; (2) studies reporting proctectomy for rectal cancer that was not a low anterior resection, such as an abdominoperineal resection and Hartman procedure; (3) overlaps between authors or institutions in the published literature; and (4) studies that lacked control arms.

\section{Statistical analysis}

Review Manager software (RevMan, version 5.2) provided by the Cochrane Collaboration was used to perform the meta-analysis. Continuous variables were pooled using the mean difference (MD) with a $95 \%$ confidence interval $(\mathrm{CI})$, and dichotomous variables were pooled using the odds ratio (OR) with a $95 \% \mathrm{CI}$. If continuous variables were reported as the median with range, we calculated the means and standard deviations according to Hozo [10]. Statistical heterogeneity was evaluated by $I^{2}$, and heterogeneity was considered high if the $I^{2}$ statistic was $>50 \%$. The fixed effects model was used for studies with low or moderate statistical heterogeneity, and the random effects model was used for studies with high statistical heterogeneity. Sensitivity analysis was performed by repeating the meta-analysis on the studies that were excluded.

\section{Results}

\section{Eligible studies}

Using the search terms, we initially retrieved 168 publications. After carefully browsing the abstracts and full texts, eight comparative studies [11-18] met all of the inclusion criteria and were eligible for meta-analysis. One comparative study [18] was excluded because it did not include patient characteristics, thus leaving seven suitable studies for the meta-analysis (Fig. 1). The seven studies [11-17] involved a total of 592 patients (324 in the R-LAR group and 268 in the L-LAR group) (Table 1). The seven studies included six non-randomized controlled trials (NRCTs) and one randomized controlled trial (RCT). The characteristics of these seven studies are listed in Table 1 . Of all the studies, two were conducted in the USA [12, 17], three in Korea [11, 13, 14], one in Italy [15], and one in Turkey [16]. The quality of all the studies was satisfactory. The results showed that R-LAR had longer operative times, lower estimated blood loss, shorter hospital stays, lower overall postoperative complications, and a significantly faster recovery of bowel function.

\section{Operative time}

All of the studies [11-17] reported operative times; the meta-analysis showed no significant difference between the two techniques $(\mathrm{MD}=28.4 ; 95 \% \mathrm{CI}=-3.48,60.27$; $P=0.08)$. The random effects model was used because of the high heterogeneity among studies $\left(I^{2}=93 \%\right)$ (Fig. 2).

\section{Length of hospital stay}

All of the studies [11-17] reported the length of hospital stay. The meta-analysis showed that R-LAR required a shorter hospital stay compared with L-LAR $(\mathrm{MD}=-1.03$; $95 \% \mathrm{CI}=-1.78,-0.28 ; P=0.007)$. The heterogeneity was high; therefore, a random effects model was utilized $\left(I^{2}=\right.$ $78 \%$ ) (Fig. 3).

\section{Conversion to open surgery}

Six studies [11-16] reported the rate of conversion to open surgery. The meta-analysis showed that R-LAR had a lower conversion rate compared with L-LAR $(\mathrm{OR}=0.07$; $95 \% \mathrm{CI}=0.02,0.31 ; P=0.0004)$ with no observed heterogeneity $\left(I^{2}=0 \%\right)$ (Fig. 4).

\section{Number of harvested lymph nodes}

Six studies [11-16] reported the number of harvested lymph nodes. The meta-analysis showed no significant difference between the two techniques $(\mathrm{MD}=-0.63$; $95 \% \mathrm{CI}=-0.78,2.05 ; P=0.38)$ with no observed heterogeneity $\left(I^{2}=0 \%\right)$ (Fig. 5). 


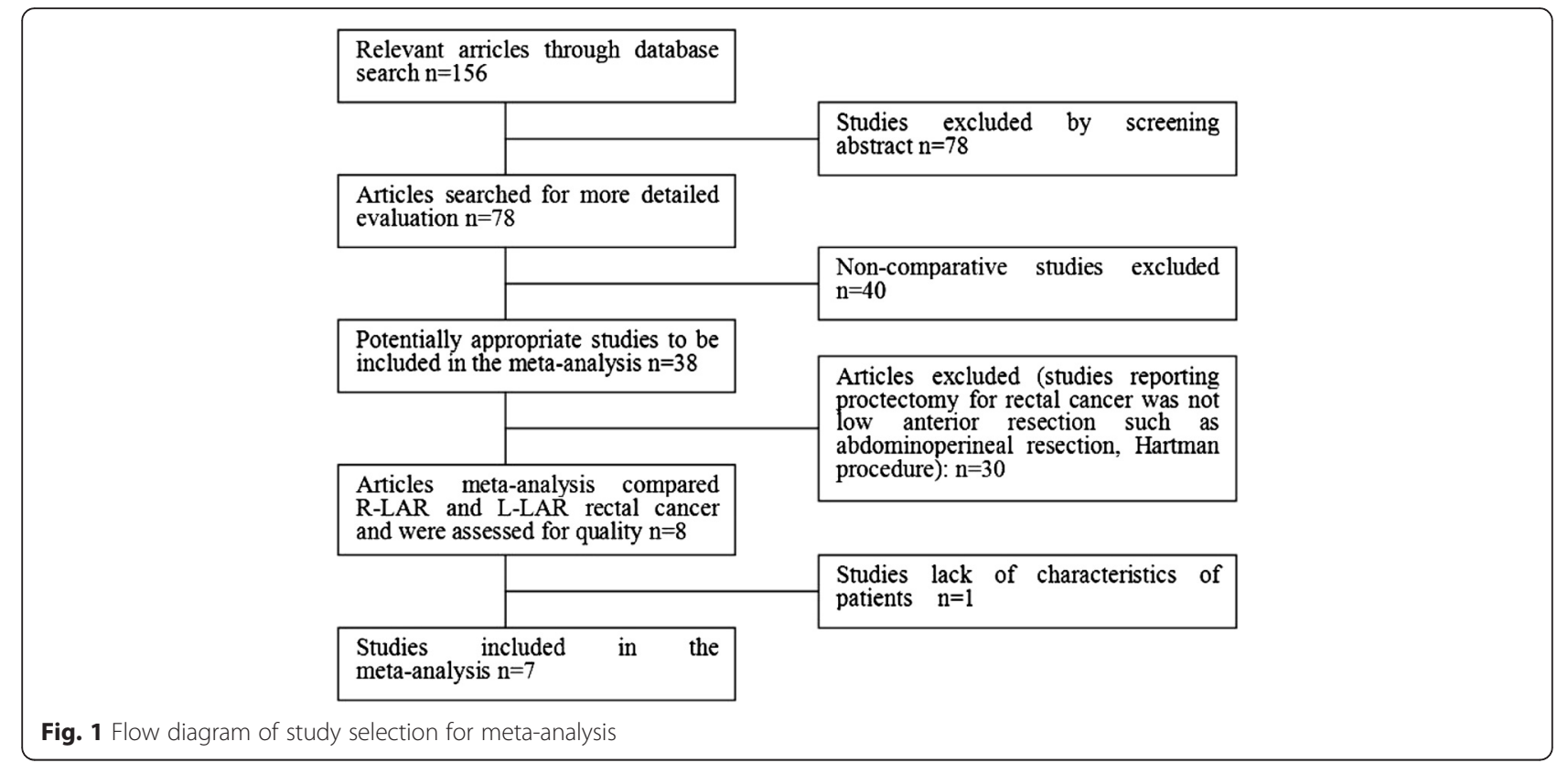

Positive circumferential resection margin involvement

Four studies [11, 14, 15, 17] reported the status of the circumferential resection margin (CRM). Circumferential resection margin involvement was found to be significantly lower in the R-LAR group than in the L-LAR group $(\mathrm{OR}=0.5 ; 95 \% \mathrm{CI}=0.25,1.01 ; P=0.05)$ with low heterogeneity $\left(I^{2}=39 \%\right)$ (Fig. 6).

\section{Post-operative complications}

All of the studies [11-17] reported the overall postoperative complication rate. The result of the metaanalysis showed that the overall complication rate was significantly lower in the RRC group ( $\mathrm{MD}=0.65 ; 95 \%$ $\mathrm{CI}=0.43,0.99 ; P=0.04)$ with no heterogeneity $\left(I^{2}=0 \%\right)$ (Fig. 7).

Table 1 Characteristics of the eight selected studies included in the meta-analysis

\begin{tabular}{|c|c|c|c|c|c|c|c|c|c|}
\hline \multirow[t]{2}{*}{ Study } & \multirow[t]{2}{*}{ Country } & \multirow[t]{2}{*}{ Group } & \multirow[t]{2}{*}{ Patients } & \multirow{2}{*}{$\begin{array}{l}\text { Mean } \\
\text { Age }\end{array}$} & \multirow{2}{*}{$\begin{array}{l}\text { Mean } \\
\text { BMl }\end{array}$} & \multirow{2}{*}{$\begin{array}{l}\text { Sex } \\
M / F\end{array}$} & \multirow{2}{*}{$\begin{array}{l}\text { CRT } \\
(\%)\end{array}$} & \multirow{2}{*}{$\begin{array}{l}\text { Study } \\
\text { Type }\end{array}$} & \multirow{2}{*}{$\begin{array}{l}\text { Anastomosis } \\
\text { Technique }\end{array}$} \\
\hline & & & & & & & & & \\
\hline \multirow[t]{2}{*}{ Park (2015) [11] } & Korea & $\mathrm{RCC}$ & 133 & 59.2 & 23.1 & $86: 47$ & 11.3 & $\mathrm{R}$ & Hybrid \\
\hline & & LRC & 84 & 63.5 & 22.9 & $60: 24$ & 11.9 & & \\
\hline \multirow[t]{2}{*}{ Pigazzi (2006) [12] } & USA & $\mathrm{RCC}$ & 6 & 60.0 & 31.0 & $2: 4$ & 33.0 & PNR & Total/hybrid \\
\hline & & LRC & 6 & 70.0 & 27.0 & $4: 2$ & 33.0 & & \\
\hline \multirow[t]{2}{*}{ Baik (2008) [13] } & Korea & $\mathrm{RCC}$ & 18 & 57.3 & 22.8 & $14: 4$ & NS & $\mathrm{RCT}$ & Hybrid \\
\hline & & LRC & 18 & 62.0 & 24.0 & $14: 4$ & NS & & \\
\hline \multirow[t]{2}{*}{ Baik (2009) [14] } & Korea & $\mathrm{RCC}$ & 56 & 60.3 & 23.4 & $37: 19$ & 8.9 & PNR & Hybrid \\
\hline & & LRC & 57 & 63.2 & 23.2 & $34: 23$ & 12.3 & & \\
\hline \multirow[t]{2}{*}{ Annibale (2013) [15] } & Italy & $\mathrm{RCC}$ & 50 & 66.0 & NS & $30: 20$ & 68.0 & PNR & Total \\
\hline & & LRC & 50 & 65.7 & NS & $30: 20$ & 56.0 & & \\
\hline \multirow[t]{2}{*}{ Erguner (2013) [16] } & Turkey & $\mathrm{RCC}$ & 27 & 54.0 & 28.3 & $14: 13$ & 14.8 & $\mathrm{R}$ & Total \\
\hline & & LRC & 37 & 61.5 & 26.7 & $20: 17$ & 8.0 & & \\
\hline \multirow[t]{2}{*}{ Marecik (2011) [17] } & USA & $\mathrm{RCC}$ & 34 & 60.0 & 28.5 & $20: 14$ & 58.8 & PNR & Hybrid \\
\hline & & LRC & 24 & 64.0 & 25.9 & $14: 10$ & 41.7 & & \\
\hline \multirow[t]{2}{*}{ Shin (2012) [18] } & Korea & $\mathrm{RCC}$ & 30 & 58.1 & 22.0 & 18:12 & NS & PNR & Total/hybrid \\
\hline & & LRC & 30 & 63.3 & 20.0 & 18:12 & NS & & \\
\hline
\end{tabular}




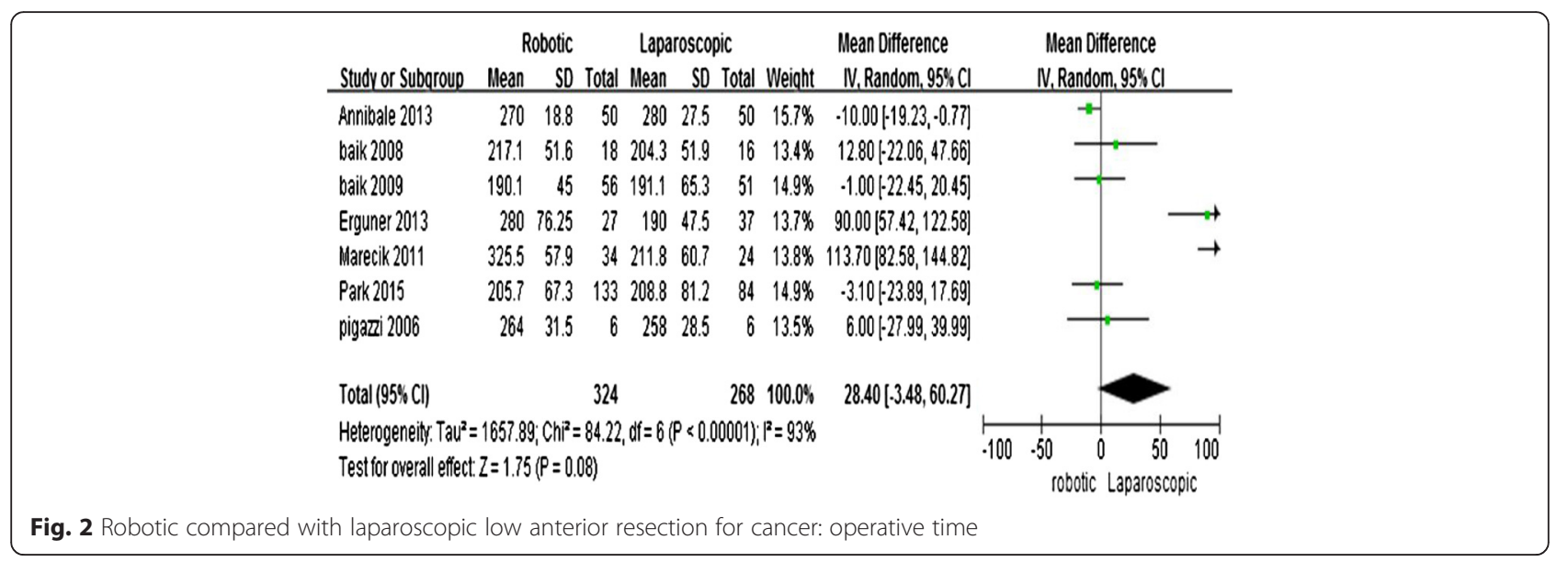

\section{Days to return of bowel function}

Three studies [11, 13, 14] reported the number of days to passing flatus. The meta-analysis showed no significant difference between the two techniques $(\mathrm{MD}=-0.15 ; 95 \% \mathrm{CI}=-0.37,0.06 ; P=0.17)$ with no observed heterogeneity $\left(I^{2}=23 \%\right)$ (Fig. 8).

\section{Discussion}

Laparoscopic colorectal surgery was first reported by Jacobs in 1991 [19] and has increasingly become a popular approach for colorectal procedures. The long-term outcomes of laparoscopic colorectal surgery have been shown to be similar to open techniques; however, laparoscopy offers better short-term outcomes [20, 21]. Some of the advantages of the laparoscopic colorectal technique over the open procedures include smaller incisions, reduction in post-operative pain and duration of ileus, quicker post-operative recovery, and earlier return to normal activity [22]. The new meta-analysis indicates that laparoscopy benefits rectal cancer patients with a shorter hospital stay, earlier return of bowel function, reduced blood loss and number of blood transfusions and lower rates of abdominal post-operative bleeding, late intestinal adhesion obstruction, and other late morbidities [23]. The laparoscopic technique still has several limitations, such as tremor, loss of three-dimensional view, poor ergonomics, and limited dexterity of movement due to the fixed instrument tips [24]. The da Vinci Surgical System has overcome these limitations and provides a three-dimensional, high-definition operative field, the steady "traction and counter-traction," reduces the physiologic tremor, and enables three extra degrees of movement using articulated instruments. However, the da Vinci Surgical System also has drawbacks, such as the loss of haptic feedback, limited range of movement of the robotic arms, time-consuming, and high cost of the system. Several studies [11, 25-27] have compared the clinical and oncologic safety and efficacy of robotic resection and laparoscopic rectal resection for cancer, but no meta-analyses have compared R-LAR with conventional L-LAR. Indeed, this is the first meta-analysis comparing the two approaches.

Although it is better to use RCTs to perform a metaanalysis, randomization is difficult to carry out in

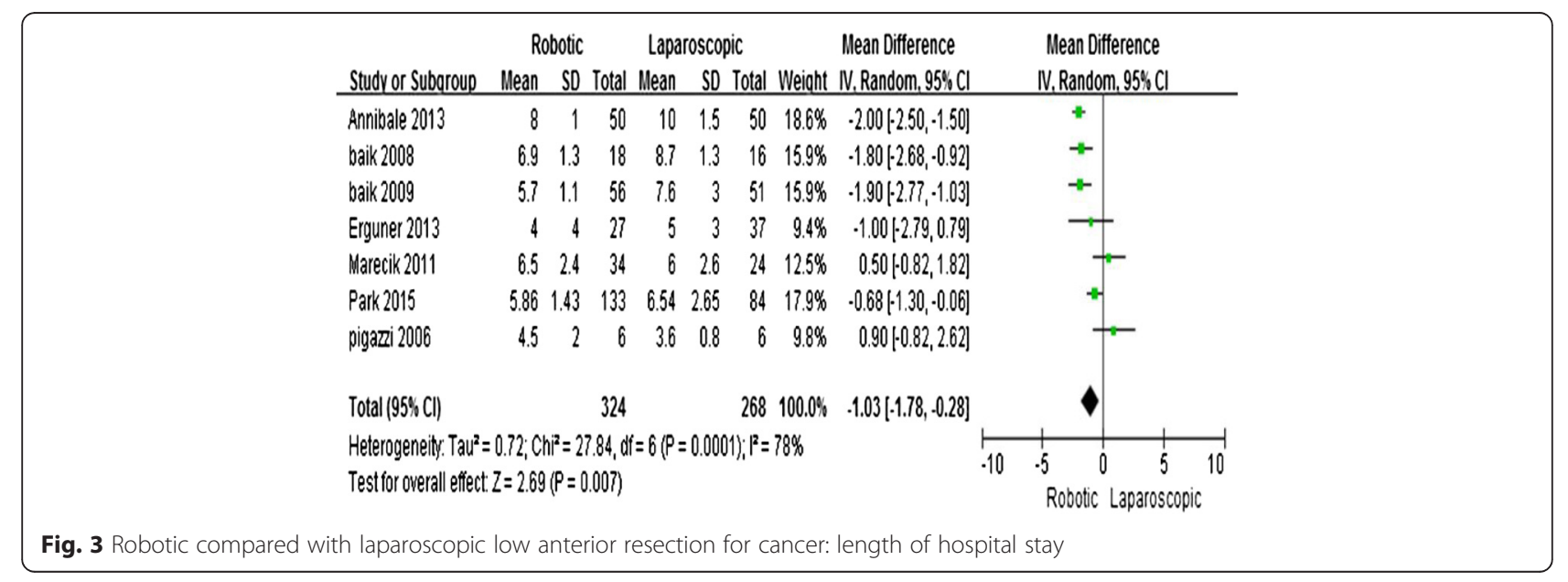




\begin{tabular}{|c|c|c|c|c|c|c|}
\hline & Study or Subaroup & $\begin{array}{c}\text { Robotic } \\
\text { Events Total }\end{array}$ & \multicolumn{2}{|c|}{ Laparoscopic } & $\begin{array}{l}\text { Odds Ratio } \\
\text { M.-H, Fixed, } 95 \% \mathrm{Cl}\end{array}$ & $\begin{array}{c}\text { Odds Ratio } \\
\text { M.H. Fixed, } 95 \% \mathrm{Cl}\end{array}$ \\
\hline & Annibale 2013 & $0 \quad 50$ & 6 & $50 \quad 27.8 \%$ & $0.07[0.00,1.24]$ & $\longleftrightarrow$ \\
\hline & baik 2008 & 18 & 2 & $18 \quad 10.5 \%$ & $0.18[0.01,3.99]$ & $\longleftarrow$ \\
\hline & baik 2009 & 56 & 6 & $57 \quad 27.6 \%$ & $0.07[0.00,1.28]$ & $\longleftarrow$ \\
\hline & Erguner 2013 & $0 \quad 27$ & 0 & $3 ?$ & Not estimable & \\
\hline & Park2015 & $0 \quad 133$ & 6 & $84 \quad 34.2 \%$ & $0.05[0.00,0.81]$ & $\longmapsto$ \\
\hline & pigazi 2006 & 06 & 0 & 6 & Notestimable & \\
\hline & Total $(95 \%$ Cl) & 290 & & $252100.0 \%$ & $0.07[0.02,0.31]$ & \\
\hline & Total events & 0 & 20 & & & \\
\hline & $\begin{array}{l}\text { Heterogeneity. Chi² } \\
\text { Test for overall effect. }\end{array}$ & $\begin{array}{l}0.43, d f=3(P= \\
Z=3.53(P=0.0\end{array}$ & $\begin{array}{l}0.93) ; 1^{2}=0 \\
0004)\end{array}$ & $0 \%$ & & $\begin{array}{lllll}0.01 & 0.1 & 1 & 10 & 100 \\
& \text { Robotic Laparoscopic }\end{array}$ \\
\hline
\end{tabular}

surgery. Therefore, NRCTs represent an acceptable alternative when performing a meta-analysis comparing two surgical techniques. We selected studies that we deemed to be of the highest methodological quality; however, selection bias may have existed because most of the studies were non-randomized and pre-operative baseline characteristics were not equal in the included studies. High heterogeneity for some outcomes may have influenced the effect of the meta-analysis; however, the significant impact of factors other than the surgical method affects these outcomes.

The heterogeneity of the length of hospital stay variable was high between studies $\left(I^{2}=78 \%\right)$. The reason for the high heterogeneity between the groups may be differences in discharge criteria from hospital or different postoperative complications. The three-dimensional, highdefinition field of view and augmented dexterity offered by the robotic approach minimizes the risk of injury of tissue and small blood vessels and leads to fewer complications, which may be related to the shorter length of hospital stay. Recently, a systematic review and meta-analysis about possible benefits of robotic surgery regarding urinary and sexual dysfunctions was reported [28], although there were few data and no randomized controlled trials support the results. Looking forward to the future randomized controlled trials could compare this area.

Operative time is considered to be long in robotic colorectal surgery because of additional set-up time, additional docking time, and the steep learning curve associated with this technique [29]. This meta-analysis showed no significant difference in operative time between the two surgical approaches. The heterogeneity in operative time between the two methods was very high $\left(I^{2}=93 \%\right)$. The set-up time was excluded in all of the studies. The reasons for high heterogeneity of operative time are as follows. (1) Some studies adopt hybrid robotic approaches, while some studies adopt full robotic approaches. (2) Specimen-retrieval techniques (natural orifice or mini-laparotomy) are different. (3) The learning curve in R-LAR is less steep than that in L-LAR procedures, and surgeons are relatively unskilled in the

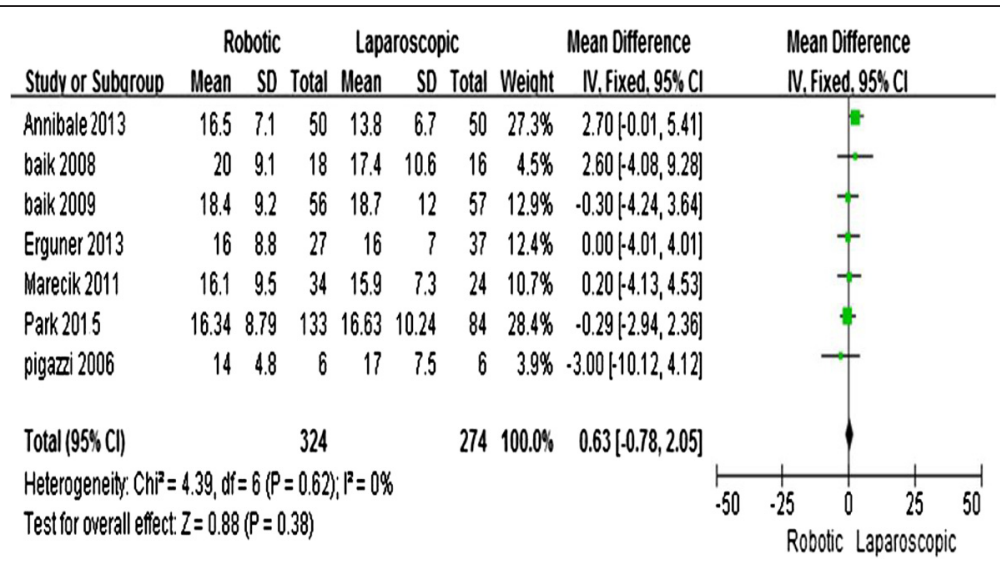

Fig. 5 Robotic compared with laparoscopic low anterior resection for cancer: number of harvested lymph nodes 


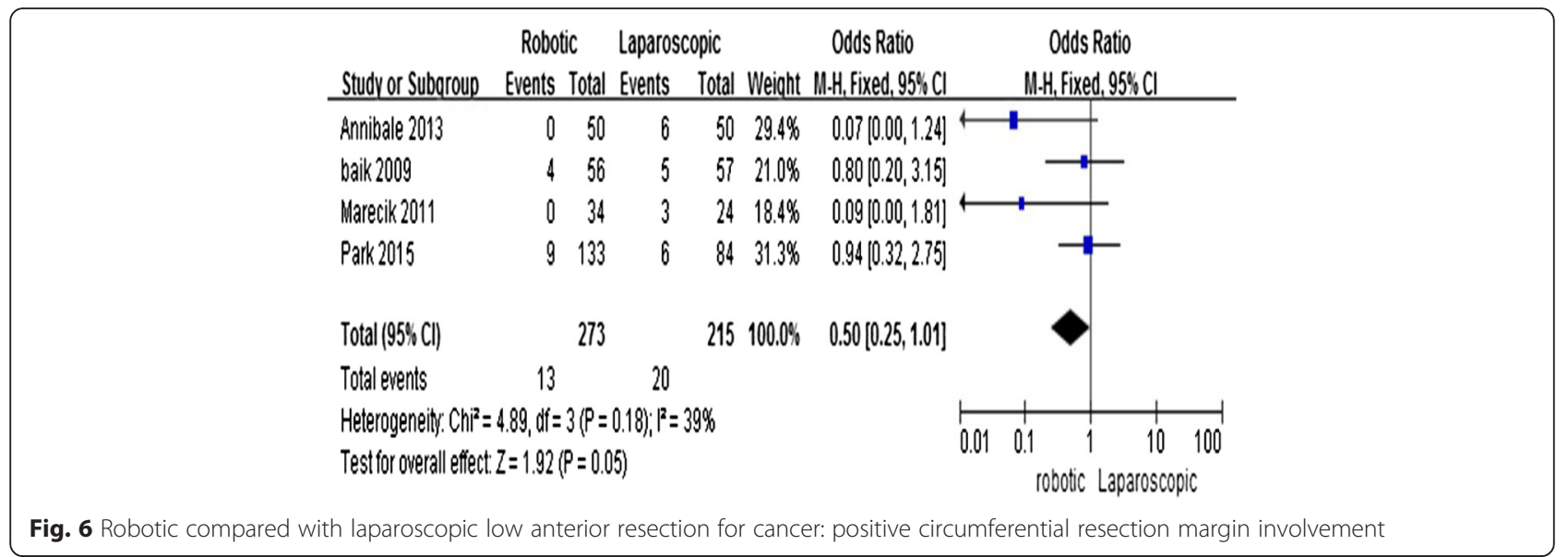

R-LAR technique [30]. As surgeons become more and more adept with the technique, the operative time for RLAR will decrease.

Local recurrence of rectal cancer after surgery is common and influences survival, and most studies involving CRM focus on local recurrence [31]. The CRM is a powerful prognostic factor for rectal cancer resection. In our study, R-LAR was associated with a lower conversion rate, lower rate of circumferential margin involvement, and lower overall complication rate. These findings may be explained by the advantages of the robotic surgical system, including the three-dimensional operative field, reduction of the physiologic tremor, and the three extra degrees of freedom in movement. In combination, these features may minimize the risk of tissue and vascular injuries. Local recurrence rate, incision recurrence rate, and overall recurrence rate are the key to the success or failure of surgery. In our meta-analysis, few studies focus on the comparison of post-operative recurrence, and it was difficult to perform subgroup analyses. We hope that more randomized controlled studies will be able to compare the post-operative recurrence rate in the future.

The major drawback of robotic surgery for rectal cancer is the cost. Initial purchasing costs, maintenance costs, and equipment costs contribute to the high price. We cannot carry out a comparative analysis of cost because few studies provide related data. A costeffectiveness analysis should be performed before this approach is widely implemented. Hottenrott [32] reported that the cost may be reduced by increasing productivity and competition. Therefore, this drawback may be overcome as the robotic approach becomes more widely used.

Our meta-analysis had some limitations. First, the meta-analysis only included one RCT and six NRCTs. The latter can bias the interpretation of the results, although the quality of the studies was deemed satisfactory [33]. Second, the number of studies and patients was relatively small, making it difficult to perform a subgroup analysis. Finally, matching patient characteristics is difficult in all of the studies, thus there is still some heterogeneity in the two groups. 


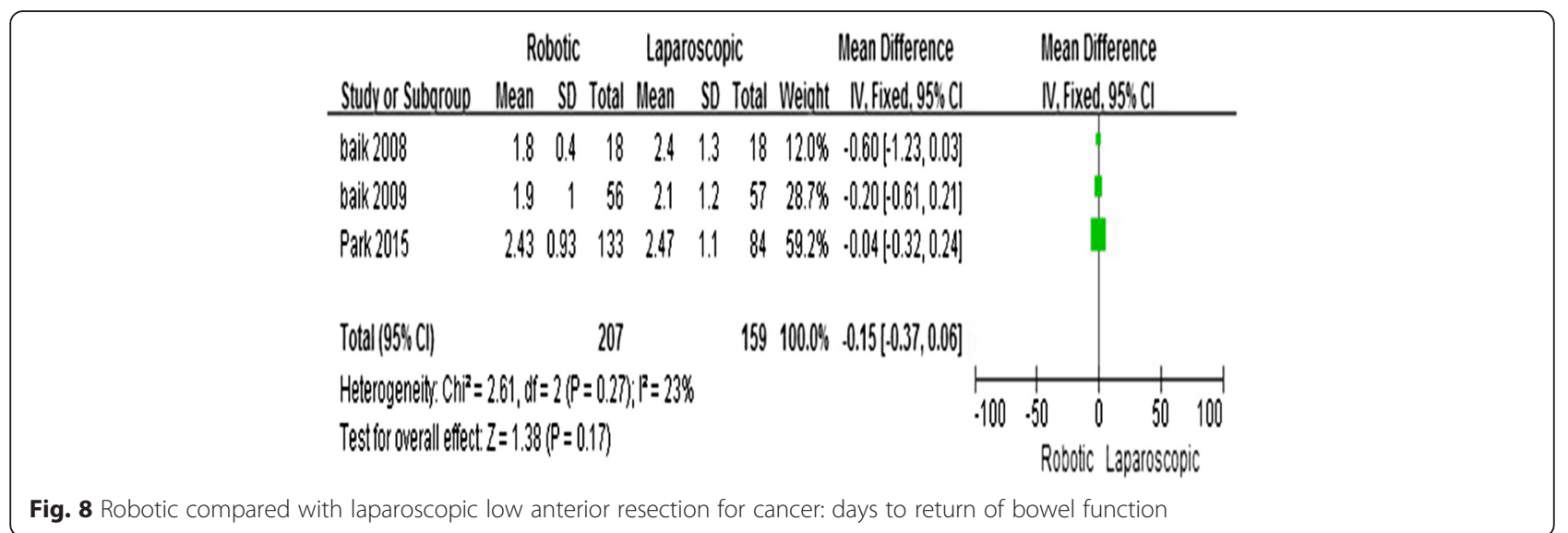

\section{Conclusions}

This meta-analysis suggests that R-LAR is associated with a shorter hospital stay, lower conversion rate, lower rate of circumferential margin involvement, and lower overall complication rate than L-LAR. There were no differences in operative time, the number of lymph nodes removed, and the number of days to return of bowel function. At present, there are larger randomized controlled trials (trial ROLARR) comparing robotic versus laparoscopic rectal resection, and we hope to have more randomized controlled studies comparing robotic and laparoscopic low anterior resection.

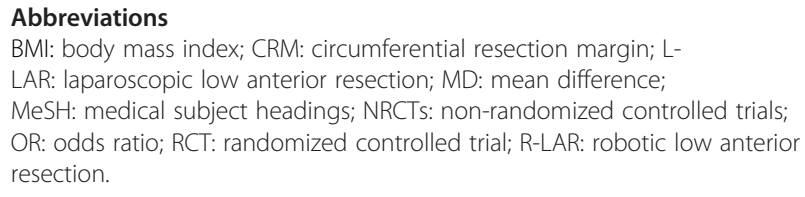

\section{Competing interests}

The authors declare that they have no competing interests.

\section{Authors' contributions}

SYL and XZF designed the research; SYL, XZF, and XHR performed the research. LZJ, HJJ, and SWT analyzed the data. SYL, Xu HR, and WJW wrote the paper. Sun YL and Xu HR equally contributed to this paper. All authors read and approved the final manuscript.

\section{Acknowledgements}

This work was supported by Grants from medical and health technology development program foundation of Shandong Province, NO. 2015 WS0149 and NO. 2015WS0197; Science and Technology development plan of Jinan, NO. 201401253; and The Natural Science Foundation of Shandong Province, NO. ZR2013HL047.

Received: 21 November 2015 Accepted: 19 February 2016

Published online: 01 March 2016

\section{References}

1. Veldkamp R, Kuhry E, Hop WC, Jeekel J, Kazemier G, Bonjer HJ, et al. Laparoscopic surgery versus open surgery for colon cancer: short-term outcomes of a randomised trial. Lancet Oncol. 2005;6:477-84.

2. Guillou PJ, Quirke P, Thorpe H, Walker J, Jayne DG, Smith AM, et al. Shortterm endpoints of conventional versus laparoscopic-assisted surgery in patients with colorectal cancer (MRC CLASICC trial): multicentre, randomised controlled trial. Lancet. 2005;365:1718-26.
3. Cadière GB, Himpens J, Germay O, Izizaw R, Degueldre M, Vandromme J, et al. Feasibility of robotic laparoscopic surgery: 146 cases. World J Surg. 2001;25:1467-77.

4. $\mathrm{Ng} \mathrm{KH}, \mathrm{Lim} \mathrm{YK}, \mathrm{Ho} \mathrm{KS}$, Ooi BS, Eu KW. Robotic-assisted surgery for low rectal dissection: from better views to better outcome. Singapore Med J. 2009:50:763-7.

5. Baek SJ, Al-Asari S, Jeong DH, Hur H, Min BS, Baik SH, et al. Robotic versus laparoscopic coloanal anastomosis with or without intersphincteric resection for rectal cancer. Surg Endosc. 2013;27:4157-63.

6. Bianchi PP, Ceriani C, Locatelli A, Spinoglio G, Zampino MG, Sonzogni A et al. Robotic versus laparoscopic total mesorectal excision for rectal cancer: a comparative analysis of oncological safety and short-term outcomes. Surg Endosc. 2010;24:2888-94.

7. Fernandez R, Anaya DA, Li LT, Orcutt ST, Balentine CJ, Awad SA, et al. Laparoscopic versus robotic rectal resection for rectal cancer in a veteran population. Am J Surg. 2013;206:509-17.

8. Clark HD, Wells GA, Huët C, McAlister FA, Salmi LR, Fergusson D, et al. Assessing the quality of randomized trials: reliability of the Jadad scale. Control Clin Trials. 1999;20:448-52.

9. Slim K, Nini E, Forestier D, Kwiatkowski F, Panis Y, Chipponi J. Methodological index for non-randomized studies (minors): development and validation of a new instrument. ANZ J Surg. 2003;73:712-6.

10. Hozo SP, Djulbegovic B, Hozo I. Estimating the mean and variance from the median, range, and the size of a sample. BMC Med Res Methodol. 2005;5:13.

11. Park EJ, Cho MS, Baek SJ, Hur H, Min BS, Baik SH, et al. Long-term oncologic outcomes of robotic low anterior resection for rectal cancer: a comparative study with laparoscopic surgery. Ann Surg. 2015;261:129-37.

12. Pigazzi A, Ellenhorn JD, Ballantyne GH, Paz IB. Robotic-assisted laparoscopic low anterior resection with total mesorectal excision for rectal cancer. Surg Endosc. 2006;20:1521-5.

13. Baik SH, Ko YT, Kang CM, Lee WJ, Kim NK, Sohn SK, et al. Robotic tumorspecific mesorectal excision of rectal cancer: short-term outcome of a pilot randomized trial. Surg Endosc. 2008:22:1601-8.

14. Baik SH, Kwon HY, Kim JS, Hur H, Sohn SK, Cho CH, et al. Robotic versus laparoscopic low anterior resection of rectal cancer: short-term outcome of a prospective comparative study. Ann Surg Oncol. 2009;16:1480-7.

15. D'Annibale A, Pernazza G, Monsellato I, Pende V, Lucandri G, Mazzocchi P, et al. Total mesorectal excision: a comparison of oncological and functional outcomes between robotic and laparoscopic surgery for rectal cancer. Surg Endosc. 2013;27:1887-95.

16. Erguner I, Aytac E, Boler DE, Atalar B, Baca B, Karahasanoglu T, et al. What have we gained by performing robotic rectal resection? Evaluation of 64 consecutive patients who underwent laparoscopic or robotic low anterior resection for rectal adenocarcinoma. Surg Laparosc Endosc Percutan Tech. 2013;23:316-9.

17. Marecik S, Zawadzki M, Velchuru VR. Cost comparison of robot-assisted versus hand assisted laparoscopic anterior resections for rectal cancer. Colorectal Dis. 2011:6:16-27.

18. Shin JY. Comparison of short-term surgical outcomes between a robotic colectomy and a laparoscopic colectomy during early experience. J Korean Soc Coloproctol. 2012;28:19-26. 
19. Jacobs M, Verdeja JC, Goldstein HS. Minimally invasive colon resection (laparoscopic colectomy). Surg Laparosc Endosc. 1991;1:144-50.

20. Fleshman J, Sargent DJ, Green E, Anvari M, Stryker SJ, Beart Jr. RW, et al. Laparoscopic colectomy for cancer is not inferior to open surgery based on 5-year data from the COST Study Group trial. Ann Surg. 2007;246:655-62.

21. Jayne DG, Guillou PJ, Thorpe H, Quirke P, Copeland J, Smith AM, et al. Randomized trial of laparoscopic-assisted resection of colorectal carcinoma: 3year results of the UK MRC CLASICC Trial Group. J Clin Oncol. 2007;25:3061-8.

22. Kuhry E, Schwenk WF, Gaupset R, Romild U, Bonjer HJ. Long-term results of laparoscopic colorectal cancer resection. Cochrane Database Syst Rev. 2008; 16(2):CD003432.

23. Trastulli S, Cirocchi R, Listorti C, Cavaliere D, Avenia N, Gullà N, et al. Laparoscopic vs open resection for rectal cancer: a meta-analysis of randomized clinical trials. Colorectal Dis. 2012;14:e277-96.

24. Choi DJ, Kim SH, Lee PJ, Kim J, Woo SU. Single-stage totally robotic dissection for rectal cancer surgery: technique and short-term outcome in 50 consecutive patients. Dis Colon Rectum. 2009:52:1824-30.

25. Kim NK, Kang J. Optimal total mesorectal excision for rectal cancer: the role of robotic surgery from an expert's view. J Korean Soc Coloproctol. 2010;26:377-87.

26. Kwak JM, Kim SH, Kim J, Son DN, Baek SJ, Cho JS. Robotic vs laparoscopic resection of rectal cancer: short-term outcomes of a case-control study. Dis Colon Rectum. 2011:54:151-6.

27. Patriti A, Ceccarelli G, Bartoli A, Spaziani A, Biancafarina A, Casciola L. Shortand medium-term outcome of robot-assisted and traditional laparoscopic rectal resection. JSLS. 2009;13:176-83.

28. Broholm M, Pommergaard HC, Gögenür I. Possible benefits of robot-assisted rectal cancer surgery regarding urological and sexual dysfunction: a systematic review and meta-analysis. Colorectal Dis. 2015;17:375-81.

29. Rencuzogullari A, Gorgun E. Robotic rectal surgery. J Surg Oncol. 2015;112:326-31.

30. D'Annibale A, Pernazza G, Morpurgo E, Monsellato I, Pende V, Lucandri G, et al. Robotic right colon resection: evaluation of first 50 consecutive cases for malignant disease. Ann Surg Oncol. 2010;17:2856-62.

31. Nagtegaal ID, Quirke P. What is the role for the circumferential margin in the modern treatment of rectal cancer? J Clin Oncol. 2008;26:303-12.

32. Hottenrott C. Robotic versus laparoscopic surgery for rectal cancer and costeffectiveness analysis. Surg Endosc. 2011;25:3954-6.

33. Maclehose RR, Reeves BC, Harvey IM, Sheldon TA, Russell IT, Black AM. A systematic review of comparisons of effect sizes derived from randomised and non-randomised studies. Health Technol Assess. 2000:4:1-154.

\section{Submit your next manuscript to BioMed Central and we will help you at every step:}

- We accept pre-submission inquiries

- Our selector tool helps you to find the most relevant journal

- We provide round the clock customer support

- Convenient online submission

- Thorough peer review

- Inclusion in PubMed and all major indexing services

- Maximum visibility for your research

Submit your manuscript at www.biomedcentral.com/submit

) Biomed Central 